\title{
Free-living energy expenditure reduced after deep brain stimulation surgery for Parkinson's disease
}

Citation for published version (APA):

Jorgensen, H. U., Werdelin, L., Lokkegaard, A., Westerterp, K. R., \& Simonsen, L. (2012). Free-living energy expenditure reduced after deep brain stimulation surgery for Parkinson's disease. Clinical Physiology and Functional Imaging, 32(3), 214-220. https://doi.org/10.1111/j.1475-097X.2011.01079.x

Document status and date:

Published: 01/05/2012

DOI:

10.1111/j.1475-097X.2011.01079.x

Document Version:

Publisher's PDF, also known as Version of record

Document license:

Taverne

Please check the document version of this publication:

- A submitted manuscript is the version of the article upon submission and before peer-review. There can be important differences between the submitted version and the official published version of record.

People interested in the research are advised to contact the author for the final version of the publication, or visit the DOI to the publisher's website.

- The final author version and the galley proof are versions of the publication after peer review.

- The final published version features the final layout of the paper including the volume, issue and page numbers.

Link to publication

\footnotetext{
General rights rights.

- You may freely distribute the URL identifying the publication in the public portal. please follow below link for the End User Agreement:

www.umlib.nl/taverne-license

Take down policy

If you believe that this document breaches copyright please contact us at:

repository@maastrichtuniversity.nl

providing details and we will investigate your claim.
}

Copyright and moral rights for the publications made accessible in the public portal are retained by the authors and/or other copyright owners and it is a condition of accessing publications that users recognise and abide by the legal requirements associated with these

- Users may download and print one copy of any publication from the public portal for the purpose of private study or research.

- You may not further distribute the material or use it for any profit-making activity or commercial gain

If the publication is distributed under the terms of Article $25 \mathrm{fa}$ of the Dutch Copyright Act, indicated by the "Taverne" license above, 


\title{
Free-living energy expenditure reduced after deep brain stimulation surgery for Parkinson's disease
}

\author{
Hans U. Jorgensen ${ }^{1}$, Lene Werdelin ${ }^{1}$, Annemette Lokkegaard ${ }^{1}$, Klaas R. Westerterp ${ }^{3}$ and Lene Simonsen ${ }^{2}$ \\ ${ }^{1}$ Department of Neurology, ${ }^{2}$ Department of Clinical Physiology, Bispebjerg Hospital, Copenhagen, Denmark, and ${ }^{3}$ Department of Human Biology, Maastricht \\ University, Maastricht, The Netherlands
}

\section{Summary}

\section{Correspondence \\ Lene Simonsen, Department of Clinical Physiology, Bispebjerg Hospital, DK-2400 Copenhagen NV, Denmark \\ E-mail: lr01@bbh.regionh.dk}

\section{Accepted for publication}

Received 29 July 2011;

accepted 30 November 2011

\section{Key words}

chronic bilateral subthalamic stimulation; doubly labelled water; energy metabolism; substrate oxidation rate; weight gain
Background: The clinical picture in Parkinson's disease (PD) is characterized by bradykinesia, rigidity, resting tremor and postural instability. In advanced stages of the disease, many patients will experience reduced efficacy of medication with fluctuations in symptoms and dyskinesias. Surgical treatment with deep brain stimulation in the subthalamic nucleus (STN-DBS) is now considered the gold standard in fluctuating PD. Many patients experience a gain of weight following the surgery. The aim of this study was to identify possible mechanisms, which may contribute to body weight gain in patients with PD following bilateral STN-DBS surgery.

Methods: Ten patients with PD were studied before bilateral STN-DBS surgery, and seven patients were studied again 3 and 12 months postoperatively. Clinical examination and resting metabolic rate with and without medical treatment was measured before and after STN-DBS. Furthermore, free-living energy expenditure, body composition, energy intake, peak oxygen consumption, maximal workload and leisure time physical activity were measured before and 3 and 12 months after surgery.

Results: The STN-DBS operated patients had a significant weight gain of $4.7 \pm 1.6 \mathrm{~kg}$ (mean $\pm \mathrm{SE}$ ) 12 months postoperatively, and the weight gain was in the fat mass. The free-living energy expenditure decreased postoperatively $13 \pm 4 \%$ even though the reported dietary intake was reduced. A decreased energy expenditure took place in the non-resting energy expenditure. The reported daily leisure time activity, peak oxygen consumption and maximal workload were unchanged.

Conclusion: The STN-DBS operated patients have a significant postoperative weight gain, as a result of a decrease in free-living energy expenditure concomitant with an insufficient decrease in energy intake.

\section{Introduction}

Parkinson's disease (PD) is a progressive neurologic disorder, which mainly affects the nigrostriatal system. The four cardinal signs in PD are bradykinesia, rigidity, resting tremor and postural instability. Dopaminergic therapies such as levodopa or dopamine agonists usually improve symptoms and signs very effectively in the first 5-7 years. However, the progression of disease is inevitable, and after years in medical treatment, many patients will experience reduced efficacy of medication.

The introduction of deep brain stimulation (DBS) of the subthalamic nucleus (STN) in the treatment of advanced, fluctuating parkinsonism has altered the treatment of late-stage PD dramatically and is now considered the most effective surgical procedure for patients with $\mathrm{PD}$ and intractable fluctuations (Krack et al., 2003). The treatment leads to a great reduction in on-off phenomena and a large improvement of L-dopa-induced dyskinesias as the anti-parkinsonian medication can be reduced considerably. Many patients experience a large gain of weight in the period following the implantation of DBS devices, where most of the studies on weight gain have focused on bilateral STN stimulation (Barichella et al., 2003; Macia et al., 2004; Perlemoine et al., 2005; Tuite et al., 2005; Montaurier et al., 2007; Walker et al., 2009b; Strowd et al., 2010; Locke 
et al., 2011) However, weight gain has also been described after unilateral STN stimulation and globus pallidus internus DBS (Walker et al., 2009a; Locke et al., 2011).Some of these patients had a low weight beforehand, so their gain has normalized the weight; others develop overweight (Barichella et al., 2003; Macia et al., 2004). In patients with documented weight gain postoperatively, the gain has been correlated with reduction in hyperkinesias (Romito et al., 2002). Subsidence of chronic tremor could cause decreased energy expenditure (Tuite et al., 2005). Macia et al. (2004) found a postoperative decrease in energy expenditure, especially for patients with many fluctuations and dyskinesias preoperatively, and the postoperative weight gain was correlated with reduction in L-dopa doses. However, a stimulatory effect on the metabolic rate of DBS cannot be excluded.

The aim of this study was to identify possible mechanisms that may contribute to body weight gain in patients with PD following bilateral STN-DBS. We therefore measured body composition, free-living energy expenditure, energy intake and resting metabolic rate in a group of patients pre- and postoperatively. Furthermore, the resting metabolic rate was measured with and without medical treatment and DBS.

\section{Material and methods}

\section{Subjects}

The study enrolled 10 patients with PD (seven men) who were operated with bilateral STN-DBS. Mean (SD) history of disease was $13.3(4 \cdot 8)$ years, and they all suffered from severe motor fluctuations that were not improved by changes in their anti-parkinsonian medication. Mean (SD) age was $61 \cdot 7$ $(6 \cdot 5)$ years. The patients were approved for surgery according to following selection criteria (Defer et al., 1999): disease duration $>5$ years, age under 70 years, excellent response to apo-morphine or levodopa challenge, no surgical contraindications, and no dementia or major ongoing psychiatric illness. Of these patients, one got a cerebral haemorrhagia during surgery and one patient did not wish to continue follow-up after surgery. One patient died 10 months after the STN-DBS surgery (complication to pneumonia). Seven patients completed the whole study, which included a pretest and a 3-and 12-month follow-up after surgery. The subjects were given a written and oral description of the study before giving their voluntary consent to participate. The Scientific Ethical Committees of The Capital Region approved the study (project nr $\mathrm{KF}(01) 259416)$.

\section{Study design}

Patients were studied before and again 3 and 12 months after STN-DBS surgery.

The following same measurements were taken over a 4-day period: On day 1, a clinical examination and an interview on health and medical history were performed. Body composition, peak oxygen consumption and leisure time physical activity were measured. In the morning on day $2-4$, resting energy expenditure (REE) was measured. In the following 14 days, the free-living energy expenditure was measured.

\section{Unified Parkinson's Disease Rating Scale}

Following the test, evaluation of signs of PD was performed using the motor component of the Unified Parkinson's Disease Rating Scale (UPDRS), which includes assessment of general bradykinesia, rigidity (neck, arms, legs) and tremor (face, hands, feet, action tremor) (Ramaker et al., 2002; Goetz et al., 2008). UPDRS III was performed before surgery in best ON with medication and without medication after withdrawal overnight (OFF). After surgery, UPDRS III was performed at three and 12 months, on three consecutive days: without medication and without STN-DBS stimulation ('off' stimulation, 'off' medication), with STN-DBS stimulation but without antiparkinsonian medication ('on' stimulation, 'off' medication) and with STN-DBS stimulation and with anti-parkinsonian medication ('on' stimulation, 'on' medication).

Stage of disease (Hoehn and Yahr) was assessed (Goetz et al., 2004).

\section{Body composition}

Patient's fat mass and fat-free mass (FFM) were determined by DEXA-scanning (Lunar DPX-IQ, software version 4.6c; Lunar Corporation, Madison, WI, USA).

\section{Resting energy expenditure}

In the evening before measurement, the anti-parkinsonian medication was paused at 20:00, and the next morning (day 2) REE was determined by indirect calorimetry in the resting and fasting (12 h) condition (defined 'off' medication). On day 3 in the morning, REE was determined again, but where the patients were on their normal anti-parkinsonian medication ('on' medication). Oxygen consumption and carbon dioxide output were measured continuously with an Oxycon Champion System using facemask and the breath-by-breath technique for a period of 30-45 min. Values for REE and substrate oxidation rates were calculated from the oxygen consumption and the respiratory exchange ratio (RER) (Ferrannini, 1988). Protein oxidation was assumed to be $60 \mathrm{~g} \mathrm{day}^{-1}$, corresponding to about $15 \%$ of basal metabolic rate (Perlemoine et al., 2005).

The measurements of REE performed 3 and 12 months after STN-DBS surgery were as follows: on day 2 without medication and without STN-DBS stimulation ('off' stimulation, 'off medication), on day 3 with STN-DBS stimulation but without anti-parkinsonian medication ('on' stimulation, 'off' medication) and on day 4 with STN-DBS stimulation and with anti-parkinsonian medication ('on' stimulation, 'on' medication). 


\section{Non-resting energy expenditure}

Non-resting energy expenditure was calculated as the total energy expenditure during free living minus REE during 'on' medication and postoperatively 'on' medication and 'on' stimulation.

\section{Total daily energy expenditure}

Free-living daily energy expenditure (DEE) was determined over a 14-day period using the doubly labelled water technique while the patients consumed their usual prescribed medication and after surgery with STN-DBS stimulation. Baseline urine samples were obtained for background measurements, and an oral dose of ${ }^{2} \mathrm{H}_{2} \mathrm{O}\left(0.125 \mathrm{~g} \mathrm{~kg}^{-1}\right.$ estimated body water $)$ and $\mathrm{H}_{2}{ }^{18} \mathrm{O}$ $\left(0.25 \mathrm{~g} \mathrm{~kg}^{-1}\right.$ estimated body water $)$ was administered in the evening of day 2. Two urine samples were obtained the following morning and 7 and 14 days later (morning urine) (Westerterp et al., 1995). The urine samples were stored at $-20^{\circ} \mathrm{C}$ until analysis took place. The isotopes deuterium $\left({ }^{2} \mathrm{H}\right)$ and oxygen-18 $\left({ }^{18} \mathrm{O}\right)$ in the urine were analysed by isotope ratio mass spectrometry (Optima; VG Isogas Ltd, Middlewich, Cheshire, UK). The carbon dioxide $\left(\mathrm{CO}_{2}\right)$ production rate was calculated from the elimination rates of the two stable isotopes using the equation of Schoeller (1988). The respiratory quotient (RQ) was taken to be equal to the food quotient of the diet and was taken as 0.85 (Black et al., 1986). The energy expenditure was calculated based on the carbon dioxide production rate and RQ.

\section{Peak oxygen consumption}

Peak oxygen consumption was determined by indirect calorimetry (Oxycon Champion; Jaeger, Wuerzburg, Germany). The subjects exercised on an electrically braced cycle ergometer (ergometrics er900; ergoline, Bitz, Germany). The initial workload was $30 \mathrm{~W}$ and was increased by $30 \mathrm{~W}$ every $2 \mathrm{~min}$ until exhaustion. Oxygen uptake and carbon dioxide output were measured using facemask and the breath-by-breath technique.

\section{Energy intake}

Energy intake was determined from a 3-day food diary. Patients were provided with a dietary scale and instructed on the measurement of food intake. The patients were strongly encouraged not to change their dietary habits during the measurement period. The calculation was performed in http:// www.madlog.dk. The energy intake was measured during the doubly labelled water measurement period.

\section{Leisure time physical activity}

The level of physical activity spent by the patients over a 7-day period was scored using a questionnaire for elderly. The questionnaire scores the activity level with regard to leisure time, household and work-related activity. Scores were calculated according to the PASE Administration and Scoring Instruction manual (Washburn et al., 1993).

\section{Statistical analysis}

All data from experiments are given as mean \pm SEM. The data were analysed by a paired t-test for each time point. $\mathrm{P}<0.05$ was considered significant.

\section{Results}

The staging scale as measured by the Hoehn and Yahr was $2 \cdot 3 \pm 0 \cdot 1$ at enrolment and did not change during the study.

\section{Preoperative}

Physical characteristics of the 10 enrolled patients are shown in Table 1. Furthermore, the parkinsonian symptoms and REE with and without anti-parkinsonian medication are shown. There was a significantly increased resting oxygen uptake with the patients 'off' drug compared with 'on' drug, and a non-significant increased REE 'off' drug compared with 'on' drug ( $P=0.065)$, while RER was unchanged.

Seven patients fulfilled the whole follow-up period, and the following postoperative results are from these seven patients.

\section{Parkinsonian symptoms}

There was, as expected, a significant improvement in UPDRS III and IV after surgery (data not shown). Anti-parkinsonian medication was reduced postoperatively; however, it did not

Table 1 Physical characteristics, parkinsonian symptoms and resting energy expenditure in the 10 preoperative patients 'on' and 'off' their anti-parkinsonian medication.

\begin{tabular}{|c|c|}
\hline$N=10$ & Preoperative \\
\hline Height $(\mathrm{cm})$ & $174 \cdot 0 \pm 2 \cdot 3$ \\
\hline Body weight (kg) & $78 \cdot 1 \pm 3 \cdot 1$ \\
\hline BMI $\left(\mathrm{kg} \mathrm{m}^{-2}\right)$ & $25 \cdot 8 \pm 0 \cdot 7$ \\
\hline Fat mass (kg) & $20 \cdot 7 \pm 1 \cdot 7$ \\
\hline Fat mass $(\%)$ & $27 \cdot 7 \pm 2 \cdot 3$ \\
\hline Fat-free mass (kg) & $57 \cdot 4 \pm 3 \cdot 1$ \\
\hline UPDRS III on drug & $19 \cdot 6 \pm 3 \cdot 1$ \\
\hline UPDRS III off drug & $41 \cdot 4 \pm 3 \cdot 4 *$ \\
\hline UPDRS IV on drug & $7 \cdot 3 \pm 0 \cdot 6$ \\
\hline L-dopa equivalent dose $\left(\mathrm{mg} \mathrm{day}^{-1}\right)$ & $878 \pm 118$ \\
\hline Resting oxygen uptake $\left(\mathrm{ml} \mathrm{min}^{-1}\right)$ on drug & $272 \pm 12$ \\
\hline Resting oxygen uptake $\left(\mathrm{ml} \mathrm{min}{ }^{-1}\right)$ off drug & $304 \pm 12 *$ \\
\hline Respiratory exchange ratio on drug & $0 \cdot 74 \pm 0 \cdot 01$ \\
\hline Respiratory exchange ratio off drug & $0 \cdot 72 \pm 0.01$ \\
\hline Resting energy expenditure on drug (MJ day ${ }^{-1}$ ) & $7 \cdot 7 \pm 0 \cdot 4$ \\
\hline Resting energy expenditure off drug (MJ day ${ }^{-1}$ ) & $8 \cdot 6 \pm 0.4$ \\
\hline
\end{tabular}

Mean \pm SEM. $*$ P $<0.05$ (pared t-test) compared with measurement on anti-parkinsonian medication. 
Table 2 Body composition and anti-parkinsonian medication before and after deep brain stimulation in the subthalamic nucleus surgery.

\begin{tabular}{|c|c|c|c|}
\hline$N=7$ & Preoperative & 3 months after & 12 months after \\
\hline $\begin{array}{l}\text { L-dopa equivalent } \\
\text { dose }\left(\mathrm{mg} \mathrm{day}^{-1}\right)\end{array}$ & $873 \pm 108$ & $551 \pm 99$ & $598 \pm 91$ \\
\hline Body weight (kg) & $79 \cdot 4 \pm 4 \cdot 4$ & $82 \cdot 7 \pm 3 \cdot 9$ & $84 \cdot 1 \pm 3 \cdot 7 *$ \\
\hline BMI $\left(\mathrm{kg} \mathrm{m}^{-2}\right)$ & $25 \cdot 5 \pm 0 \cdot 9$ & $26 \cdot 5 \pm 0 \cdot 8$ & $27 \cdot 0 \pm 0 \cdot 8^{*}$ \\
\hline Fat mass $(\mathrm{kg})$ & $19 \cdot 6 \pm 1 \cdot 9$ & $22 \cdot 6 \pm 2 \cdot 3 *$ & $23.5 \pm 2.5 *$ \\
\hline Fat mass $(\%)$ & $25 \cdot 7 \pm 2 \cdot 1$ & $28 \cdot 4 \pm 2 \cdot 7 *$ & $29 \cdot 0 \pm 2 \cdot 9$ \\
\hline Fat-free mass $(\mathrm{kg})$ & $59 \cdot 8 \pm 3 \cdot 7$ & $60 \cdot 1 \pm 3 \cdot 6$ & $60 \cdot 6 \pm 3 \cdot 2$ \\
\hline
\end{tabular}

Mean \pm SEM. $* \mathrm{P}<0.05$ (pared $\mathrm{t}$-test) compared with preoperative values.

reach significance $(P=0.064$ after 3 months and $P=0.072$ after 12 months) (Table 2).

\section{Body composition}

There was a significant increase in body weight at $4.7 \mathrm{~kg}$ (range $2 \cdot 0-11.5 \mathrm{~kg}$ ) 12 months after the operation, and the increase took place in the fat mass whereas the FFM was unchanged (Table 2).

\section{Resting energy expenditure}

During anti-parkinsonian medication was the preoperative resting oxygen consumption $\left(\mathrm{VO}_{2}\right) 283 \pm 13 \mathrm{ml} \mathrm{min}^{-1}$, the REE $8.00 \pm 0.3 \mathrm{MJ} \mathrm{day}^{-1}$ and the RER $0.75 \pm 0.2$, and these parameters did not change significantly 'on' drug/'on' stimulation 3 and 12 months postoperatively. In Fig. 1 is shown the $\mathrm{VO}_{2}$, REE and RER 3 and 12 months after surgery.

Three and 12 months after operation, there were no significant differences in $\mathrm{VO}_{2}$ and REE comparing values 'on' drug/'on' stimulation with values 'off' drug/'off' stimulation and 'off' drug/'on' stimulation (Fig. 1). However, during STNDBS stimulation, the RER was significantly increased compared with off drug/'off stimulation three and 12 months after surgery (Fig. 1).

\section{Substrate oxidation rates}

The substrate oxidation rates after surgery is shown in Fig. 2. Preoperatively, there was no significant difference in fasting carbohydrate oxidation or lipid oxidation during anti-parkinsonian medication ('on' drug) compared with 'off' drug (data not shown). After the operation, the resting fasting lipid oxidation decreased significantly when the patients were 'on' stimulation compared with 'off' drug/'off' stimulation at both 3 and 12 months visit (Fig. 2).

\section{Daily energy expenditure}

The DEE is shown in Table 3. The free-living DEE decreased, although not significantly 3 months after surgery $(P=0.053)$
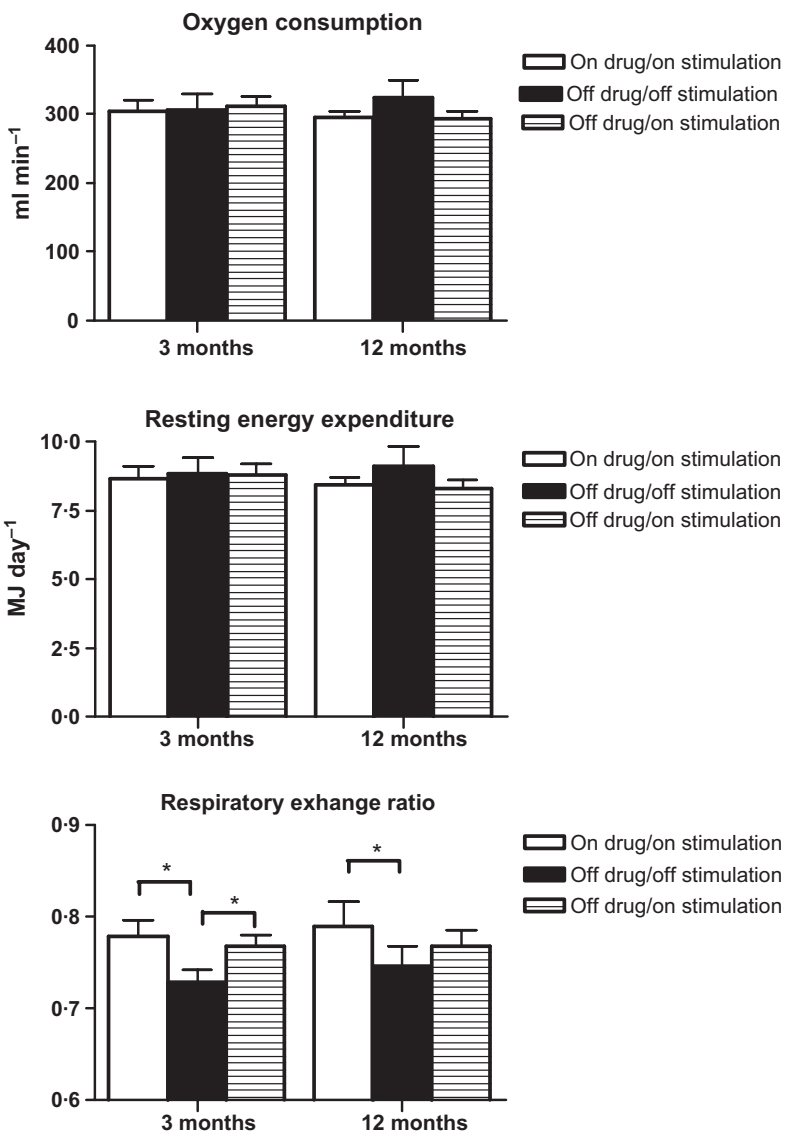

Figure 1 Whole-body fasting oxygen consumption, resting energy expenditure and respiratory exchange ratio 3 and 12 months after the deep brain stimulation in the subthalamic nucleus (STN-DBS) surgery: Open bars are with the patients on DBS and on their antiparkinsonian medication. Closed bars are with the patients without DBS and without their anti-parkinsonian medication for $12 \mathrm{~h}$. Hatched bars are with the patients without their anti-parkinsonian medication for $12 \mathrm{~h}$ but during DBS.

and was significantly decreased with $13 \pm 4 \% 12$ months after the operation compared with the preoperative value (Table 3).

\section{Non-resting energy expenditure}

The non-resting energy expenditure is the amount of the DEE not coming from REE when the patients are 'on' medication and postoperatively 'on' medication and 'on' stimulation. It was significantly decreased by $42 \pm 9 \% 3$ months after surgery and by $41 \pm 8 \% \quad 12$ months after surgery compared with the preoperative value (Table 3 ).

\section{Daily energy intake}

The reported daily energy intake (DEI) decreased significantly 12 months after the operation compared with preoperative values (Table 3). The reported DEI accounted for about $70 \%$ of the DEE. 

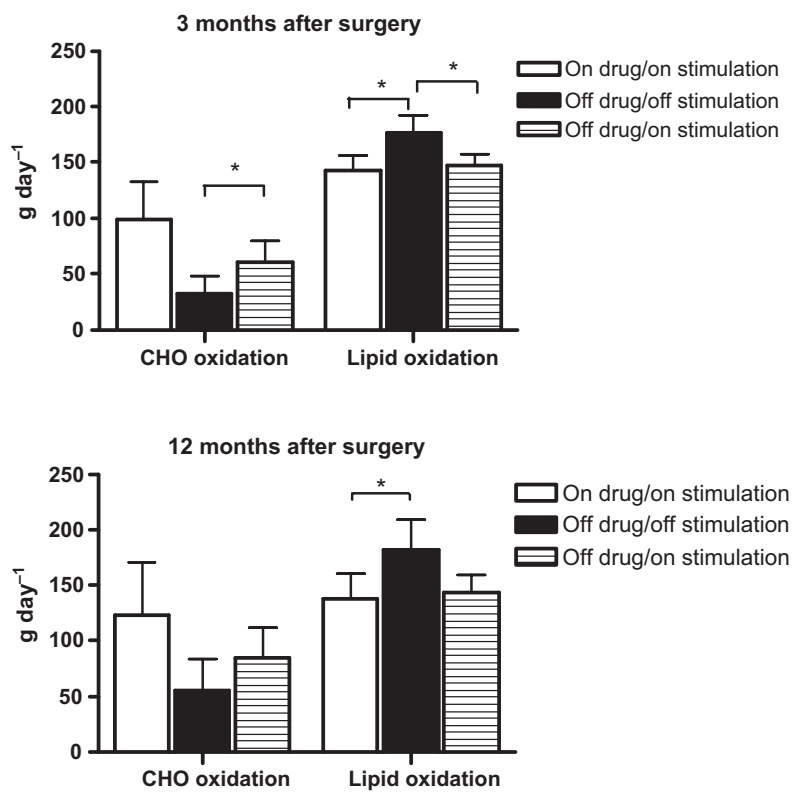

Figure 2 Whole-body fasting substrate oxidation rates 3 and 12 months after the deep brain stimulation in the subthalamic nucleus (STN-DBS) surgery: Open bars are with the patients on DBS and on their anti-parkinsonian medication. Closed bars are with the patients without DBS and without their anti-parkinsonian medication for $12 \mathrm{~h}$. Hatched bars are with the patients without their anti-parkinsonian medication for $12 \mathrm{~h}$ but during DBS.

Table 3 Daily free-living energy expenditure (DEE), non-resting energy expenditure (non-REE), reported daily energy intake (DEI), peak oxygen uptake, maximal workload and reported physical activity (PASE) before and after deep brain stimulation in the subthalamic nucleus surgery.

\begin{tabular}{lccc}
\hline $\boldsymbol{N}=\mathbf{7}$ & Preoperative & $\begin{array}{c}\mathbf{3} \text { months } \\
\text { after }\end{array}$ & $\begin{array}{c}\mathbf{1 2} \text { months } \\
\text { after }\end{array}$ \\
\hline DEE $\left(\mathrm{MJ} \mathrm{day}{ }^{-1}\right)$ & $13 \cdot 3 \pm 1 \cdot 1$ & $11 \cdot 4 \pm 0 \cdot 6$ & $11 \cdot 3 \pm 0 \cdot 6^{*}$ \\
Non-REE $\left(\mathrm{MJ} \mathrm{day}^{-1}\right)$ & $5 \cdot 2 \pm 0 \cdot 9$ & $2 \cdot 7 \pm 0 \cdot 4^{*}$ & $2 \cdot 9 \pm 0 \cdot 5^{*}$ \\
DEI $\left.(\mathrm{MJ} \mathrm{day})^{-1}\right)$ & $10 \cdot 1 \pm 1 \cdot 0$ & $8 \cdot 6 \pm 1 \cdot 1$ & $8 \cdot 0 \pm 0 \cdot 6 *$ \\
Peak $\mathrm{VO}_{2}\left(\mathrm{l} \mathrm{min}^{-1}\right)$ & $2 \cdot 4 \pm 0 \cdot 4$ & $2 \cdot 4 \pm 0 \cdot 4$ & $2 \cdot 4 \pm 0 \cdot 2$ \\
Peak $\mathrm{VO}_{2}\left(\mathrm{ml} \mathrm{kg}^{-1} \mathrm{~min}^{-1}\right)$ & $30 \pm 4$ & $28 \pm 3$ & $28 \pm 2$ \\
Maximal workload (W) & $138 \pm 27$ & $146 \pm 22$ & $139 \pm 15$ \\
PASE & $174 \pm 25$ & $148 \pm 12$ & $159 \pm 26$ \\
\hline
\end{tabular}

Mean \pm SEM. $* \mathrm{P}<0.05$ (pared t-test) compared with preoperative values.

\section{Peak oxygen uptake and maximal workload}

The peak oxygen uptake and maximal workload is shown in Table 3. There was no difference in peak oxygen uptake or maximal workload during the study period.

\section{Leisure time physical activity}

The physical activity score did not change significantly 3 or 12 months after surgery (Table 3).

\section{Discussion}

This study is the first long-term prospective study, where freeliving energy expenditure has been extensively evaluated before and 3 and 12 months after STN-DBS surgery. All patients experienced a much better motor performance similar to previously reported studies with effect on levodopa-responsive perkinsonian features such as bradykinesia, tremor and rigidity with a reduction in the need for anti-parkinsonian medication (Limousin et al., 1998; Moro et al., 1999).

The main finding is that the STN-DBS operated patients had a significant weight gain postoperatively and that the weight gain was taking place in the fat mass. This is in agreement with a recent study (Bannier et al., 2009), where patients were examined before and 3 and 16 months after STN-DBS operation. The increase in weight was attributed to a decrease in total energy expenditure concomitant with an insufficient decrease in energy intake. Furthermore, the decrease in total energy expenditure was taking place in the non- REE.

During weight stable conditions, the energy intake is equal to the energy used (total energy expenditure). If an individual is in positive energy balance, there will be a weight gain because of storing of energy.

The decrease in total energy expenditure after surgery in the present study was about $2 \mathrm{MJ}$ day $^{-1}$, which theoretically would led to a weight gain at about $20 \mathrm{~kg}$ after 1 year assuming unchanged daily caloric intake postoperatively, and all the extra energy deposited as fat.

Only very few earlier studies have measured free-living energy expenditure in patients with $\mathrm{PD}$ using the doubly labelled water technique (Toth et al., 1997; Delikanaki-Skaribas et al., 2009). The mean DEE in these studies was about $25 \%$ lower than in the present study. However, in these studies they investigated patients on levodopa medication without severe dyskinesias. Therefore, this discrepancy can be explained by difference in weight, age and severe dyskinesias as our patients were candidates for operation.

An earlier study (Montaurier et al., 2007) has measured the effect of STN-DBS on the DEE evaluated in a calorimetric chamber before and 3 months after surgery. They found a significant reduction by about $9 \%$, and although this result was under controlled conditions, it is in accordance with the present results. Furthermore, they found unchanged REE 3 months postoperatively in accordance with the results in the present study, where the REE with the patients on anti-parkinsonian medication and on brain stimulation did not change three and 12 months after STN-DBS surgery. In two earlier studies (Toth et al., 1997; Delikanaki-Skaribas et al., 2009), REE was measured during indirect calorimetry. In these studies, they found a value about $20 \%$ lower than that found in the present study. Increased rigidity, dystonia and tremor with more severe PD in our study may account for the higher REE in comparison with these other studies.

To investigate whether the medication or the brain stimulation per se after surgery influences the REE, we measured the REE 
during different situations in the two postoperative measurements (Fig. 1). We found that the REE was not significantly different during 'off' medication and 'off' stimulation compared with the values 'on' medication and 'on' stimulation. This is in contrast to the results by others (Perlemoine et al., 2005; Montaurier et al., 2007), but the discrepancy is probably due to differences in the two studies as the other study investigated the patients during acute L-dopa challenge and acute brain stimulation (30 min), while in our study the 'off/off' measurements were performed after the stimulation, and anti-parkinsonian medication was removed for $12 \mathrm{~h}$ before the measurements. The present study also showed that the DBS per se significantly decreased the lipid oxidation rate during 'on' stimulation. This change in substrate oxidation rate has been observed by others (Perlemoine et al., 2005). There is no obvious explanation for the shift in substrate oxidation rates. However, measurements on rats after $30 \mathrm{~s}$ of electrical stimulation of the hypothalamus showed increases in energy expenditure and increases in RER, suggesting that the hypothalamic activity influences which substrate the rat uses for energy and that hypothalamus forms part of body weight regulation (Atrens et al., 1987).

The reported daily physical activity level and the fitness as measured by peak oxygen uptake were unchanged postoperatively. The patients improved their motor function postoperatively (UPDRS III), and in general these patients improve their physical activity so it cannot be excluded that the scale used has a too low sensitivity in this type of patients, or the number of subjects was too low. On the other hand, all the investigated patients increased their body weight postoperatively.

Under-reporting of food intake is frequent and has earlier been shown by the doubly labelled water method (Schoeller, 1990; Trabulsi \& Schoeller, 2001; Ferriolli et al., 2010). In an earlier review, they found about 25\% under-reporting under different conditions. In our study, the under-reporting was about $25 \%$ and not significantly different in the pre- and postoperative period. The reported dietary intake was significantly decreased at 12 months postoperatively in spite of weight gain in the same period. This suggest that the positive weight balance postoperatively in the STN-DBS patients is not because of increased appetite and thereby increased energy intake as proposed in an earlier abstract by Barichella et al. (2002). Nevertheless, in a later article from the same group they found that the weight gain after STN-DBS operation was independent of increase in appetite and therefore an unlikely explanation (Barichella et al., 2003), which has been con- firmed by other prospective studies (Montaurier et al., 2007; Sauleau et al., 2009). However, inaccuracy of self-reported intakes should prompt caution in the interpretation of the result.

The study has shown that the DEE decreases after STN-DBS surgery, so a likely explanation of the weight gain is that brain stimulation induces an imbalance between energy intake and energy expenditure. It can be speculated whether STN DBS per se has a central 'weight modifying' effect, as proposed in recent studies (Strowd et al., 2010; Locke et al., 2011). The expected postoperative weight gain can be prevented by nutritional intervention starting up early after the operation if weight gain is not welcome (Guimaraes et al., 2009).

The patients were in positive energy balance during the study, and the indirect measurements of energy expenditure assume steady state. However, the measurements of free-living energy expenditure were taken during 14 days, and in this period, the weight gain was on average $0 \cdot 2 \mathrm{~kg}$. This will only influence the $\mathrm{RQ}$ and energy equivalent of carbon dioxide with $<1 \%$ (Elia, 1991).

\section{Limitations}

This study is one of the few long-term prospective studies where energy intake and energy expenditure have been extensively evaluated before and after STN-DBS. However, the number of patients is limited, so there can be risk of type 2 statistical errors.

\section{Conclusion}

The STN-DBS operated patients have a significant postoperative weight gain, and the weight gain is taking place in the fat mass. The increase in weight is attributed to a decrease in free-living energy expenditure concomitant with a simultaneous insufficient decrease in energy intake. The marked changes in freeliving DEE observed after STN-DBS operation in Parkinson patients may have important implications in terms of practical and clinical recommendations for reducing energy intake if weight gain is not welcome postoperatively.

\section{Acknowledgment}

The study was founded by the Danish Parkinson Foundation and Foundation for Research in Neurology.

\section{References}

Atrens DM, Siviy SM, Holmes LJ, Solowij N, Jirasek M. Hypothalamic modulation of thermogenesis and energy substrate utilization. Brain Res Bull (1987); 18: 303308.

Bannier S, Montaurier C, Derost PP, Ulla M, Lemaire JJ, Boirie Y, Morio B, Durif F. Overweight after deep brain stimulation of the subthalamic nucleus in Parkinson disease: long term follow-up. J Neurol Neurosurg Psychiatry (2009); 80: 484-488.

Barichella M, Marczewska AM, Mariani C, Landi A, Vairo A, Pezzoli G. Body weight gain in patients with Parkinson's disease and deep brain stimulation. Mov Disord (2002); 17(Suppl. 5): S125-S126.

Barichella M, Marczewska AM, Mariani C, Landi A, Vairo A, Pezzoli G. Body weight gain rate in patients with Parkinson's disease and deep brain stimulation. Mov Disord (2003); 18: 1337-1340.

Black AE, Prentice AM, Coward WA. Use of food quotients to predict respiratory quotients for the doubly-labelled water method of measuring energy expenditure. Hum Nutr Clin Nutr (1986); 40: 381-391.

Defer GL, Widner H, Marie RM, Remy P, Levivier M. Core assessment program for 
surgical interventional therapies in Parkinson's disease (CAPSIT-PD). Mov Disord (1999); 14: 572-584.

Delikanaki-Skaribas E, Trail M, Wong WW, Lai EC. Daily energy expenditure, physical activity, and weight loss in Parkinson's disease patients. Mov Disord (2009); 24: 667-671.

Elia M. Energy equivalents of $\mathrm{CO} 2$ and their importance in assessing energy expenditure when using tracer techniques. Am J Physiol (1991); 260: E75-E88.

Ferrannini E. The theoretical bases of indirect calorimetry: a review. Metabolism (1988); 37: 287-301.

Ferriolli E, Pfrimer K, Moriguti JC, Lima NK, Moriguti EK, Formighieri PF, Scagliusi FB, Marchini JS. Under-reporting of food intake is frequent among Brazilian free-living older persons: a doubly labelled water study. Rapid Commun Mass Spectrom (2010); 24: $506-$ 510.

Goetz CG, Poewe W, Rascol O, Sampaio C, Stebbins GT, Counsell C, Giladi N, Holloway RG, Moore CG, Wenning GK, Yahr MD, Seidl L. Movement Disorder Society Task Force report on the Hoehn and Yahr staging scale: status and recommendations. Mov Disord (2004); 19: 1020-1028.

Goetz CG, Tilley BC, Shaftman SR, Stebbins GT, Fahn S, Martinez-Martin P, Poewe W, Sampaio C, Stern MB, Dodel R, Dubois B, Holloway R, Jankovic J, Kulisevsky J, Lang AE, Lees A, Leurgans S, LeWitt PA, Nyenhuis D, Olanow CW, Rascol O, Schrag A, Teresi JA, van Hilten JJ, LaPelle N. Movement Disorder Societysponsored revision of the Unified Parkinson's Disease Rating Scale (MDS-UPDRS): scale presentation and clinimetric testing results. Mov Disord (2008); 23: 2129-2170.

Guimaraes J, Matos E, Rosas MJ, Vieira-Coelho A, Borges N, Correia F, Vaz R, Garrett C. Modulation of nutritional state in Parkinsonian patients with bilateral subthalamic nucleus stimulation. J Neurol (2009); 256: 2072-2078.

Krack P, Batir A, Van BN, Chabardes S, Fraix V, Ardouin C, Koudsie A, Limousin PD, Benazzouz A, LeBas JF, Benabid AL, Pollak P. Fiveyear follow-up of bilateral stimulation of the subthalamic nucleus in advanced Parkinson's disease. N Engl J Med (2003); 349: 1925-1934.

Limousin P, Krack P, Pollak P, Benazzouz A, Ardouin C, Hoffmann D, Benabid AL. Electrical stimulation of the subthalamic nucleus in advanced Parkinson's disease. N Engl J Med (1998); 339: 1105-1111.

Locke MC, Wu SS, Foote KD, Sassi M, Jacobson CE, Rodriguez RL, Fernandez HH, Okun MS. Weight changes in subthalamic nucleus vs globus pallidus internus deep brain stimulation: results from the COMPARE Parkinson disease deep brain stimulation cohort. Neurosurgery (2011); 68: 1233-1237.

Macia F, Perlemoine C, Coman I, Guehl D, Burbaud P, Cuny E, Gin H, Rigalleau V, Tison F. Parkinson's disease patients with bilateral subthalamic deep brain stimulation gain weight. Mov Disord (2004); 19: 206-212.

Montaurier C, Morio B, Bannier S, Derost P, Arnaud P, Brandolini-Bunlon M, Giraudet C, Boirie Y, Durif F. Mechanisms of body weight gain in patients with Parkinson's disease after subthalamic stimulation. Brain (2007); 130: 1808-1818.

Moro E, Scerrati M, Romito LM, Roselli R, Tonali P, Albanese A. Chronic subthalamic nucleus stimulation reduces medication requirements in Parkinson's disease. Neurology (1999); 53: 85-90.

Perlemoine C, Macia F, Tison F, Coman I, Guehl D, Burbaud P, Cuny E, Baillet L, Gin H, Rigalleau V. Effects of subthalamic nucleus deep brain stimulation and levodopa on energy production rate and substrate oxidation in Parkinson's disease. Br J Nutr (2005); 93: 191-198.

Ramaker C, Marinus J, Stiggelbout AM, Van Hilten BJ. Systematic evaluation of rating scales for impairment and disability in Parkinson's disease. Mov Disord (2002); 17: 867-876.

Romito LM, Scerrati M, Contarino MF, Bentivoglio AR, Tonali P, Albanese A. Long-term follow up of subthalamic nucleus stimulation in Parkinson's disease. Neurology (2002); 58: 1546-1550.

Sauleau P, Leray E, Rouaud T, Drapier S, Drapier D, Blanchard S, Drillet G, Peron J, Verin M. Comparison of weight gain and energy intake after subthalamic versus pallidal stimulation in Parkinson's disease. Mov Disord (2009); 24: 2149-2155.

Schoeller DA. Measurement of energy expenditure in free-living humans by using doubly labeled water. J Nutr (1988); 118 : 1278-1289.

Schoeller DA. How accurate is self-reported dietary energy intake? Nutr Rev (1990); 48: 373-379.

Strowd RE, Cartwright MS, Passmore LV, Ellis TL, Tatter SB, Siddiqui MS. Weight change following deep brain stimulation for movement disorders. J Neurol (2010); 257: 1293-1297.

Toth MJ, Fishman PS, Poehlman ET. Free-living daily energy expenditure in patients with Parkinson's disease. Neurology (1997); 48: 88-91.

Trabulsi J, Schoeller DA. Evaluation of dietary assessment instruments against doubly labeled water, a biomarker of habitual energy intake. Am J Physiol Endocrinol Metab (2001); 281: E891-E899.

Tuite PJ, Maxwell RE, Ikramuddin S, Kotz CM, Billington CJ, Laseski MA, Thielen SD. Weight and body mass index in Parkinson's disease patients after deep brain stimulation surgery. Parkinsonism Relat Disord (2005); 11: 247-252.

Walker HC, Lyerly M, Cutter G, Hagood J, Stover NP, Guthrie SL, Guthrie BL, Watts RL. Weight changes associated with unilateral STN DBS and advanced PD. Parkinsonism Relat Disord (2009a); 15: 709-711.

Walker HC, Watts RL, Guthrie S, Wang D, Guthrie BL. Bilateral effects of unilateral subthalamic deep brain stimulation on Parkinson's disease at 1 year. Neurosurgery (2009b); 65: 302-309.

Washburn RA, Smith KW, Jette AM, Janney CA. The Physical Activity Scale for the Elderly (PASE): development and evaluation. J Clin Epidemiol (1993); 46: 153-162.

Westerterp KR, Wouters L, van Marken Lichtenbelt WD. The Maastricht protocol for the measurement of body composition and energy expenditure with labeled water. Obes Res (1995); 3(Suppl. 1): 49-57. 